Original Research Article

\title{
Awareness regarding the importance of vitamin D and prevention of its deficiency among female undergraduate medical students
}

\author{
Nida Nowreen $^{1 *}$, Reqaya Hameed ${ }^{2}$
}

${ }^{1}$ Department of Physiology, Government Medical College, Srinagar, Jammu and Kashmir, India

${ }^{2}$ Department of Physiology, Sher-i-Kashmir Institute of Medical Sciences, Bemina, Srinagar, Jammu and Kashmir, India

Received: 08 April 2019

Accepted: 18 April 2019

*Correspondence to:

Dr. Nida Nowreen,

Email: nowreen.n3@gmail.com

Copyright: () the author(s), publisher and licensee Medip Academy. This is an openaccess article distributed under the terms of the Creative Commons Attribution NonCommercial License, which permits unrestricted noncommercial use, distribution, and reproduction in any medium, provided the original work is properly cited.

\begin{abstract}
Background: Vitamin D deficiency is a common nutritional disorder that has assumed epidemic proportion. One of the major reasons for the worldwide spread of this disorder has been deficient awareness about the importance of vitamin D, its benefits on health, and prevention of deficiency state across different populations. Vitamin D deficiency (VDD) is widely prevalent in this part of the country (Kashmir valley, India), the prevalence being higher in females. This study was conducted to assess the awareness of female medical students regarding the importance of vitamin D and the prevention of its deficiency among them.

Methods: This cross-sectional study was carried out among 113 female medical students. A self-administered questionnaire consisting of two parts was used to collect data. The first part was for identifying socio-demographic characters and the second half was a 12-question, multiple-choice survey focussing on vitamin D. Data was entered and analysed using computer software MS Excel.

Results: The results of the study showed that the participants had good knowledge regarding some aspects while knowledge for other aspects was poor. The majority of participants had adequate knowledge about main source/dietary source of vitamin $\mathrm{D}$, the site of synthesis, effect of vitamin $\mathrm{D}$ on bone health, main effects of deficiency on bone health, identification of high-risk groups and importance of supplements in management of deficiency. However, majority had inadequate knowledge about the epidemic state of VDD, RDA, time/duration of sun exposure and other effects of deficiency.

Conclusions: The present study showed that there are some gaps in awareness about vitamin D, its benefits, and management of deficiency among female medical students.
\end{abstract}

Keywords: Awareness, Medical students, Sun exposure, Supplements, Vitamin D

\section{INTRODUCTION}

Vitamin D deficiency is a common nutritional disorder that has assumed epidemic proportion worldwide with an estimated one billion people having either vitamin D deficiency or insufficiency. ${ }^{1,2}$ The prevalence of vitamin D deficiency in India has been estimated to range from $50 \%$ to $90 \%$ across different age groups in both sexes. ${ }^{3-5}$

Vitamin D is a fat-soluble vitamin (sunshine vitamin), known for its antirachitic activity. ${ }^{6}$ Vitamin D, in general, refers to Vitamin D3 which can be synthesized endogenously. Around $90 \%$ of the required Vitamin D is synthesized in the skin under sun exposure. ${ }^{7,8}$ Synthesis of vitamin in skin on exposure to UV-B is affected by many factors that include latitude, solar zenith angle, atmospheric pollution, ozone layer, and melanin pigmentation. ${ }^{9}$

When an individual becomes vitamin $\mathrm{D}$ deficient, intestinal calcium and phosphorous absorption decrease, serum ionized calcium levels drop, and synthesis of 
parathyroid hormone (PTH) is stimulated. Increased plasma PTH maintains serum calcium in the normal range by enhancing renal production of $1,25(\mathrm{OH})_{2} \mathrm{D}$, increasing bone turnover, accelerating bone loss, and promoting tubular calcium reabsorption and phosphate excretion. Increased $1,25(\mathrm{OH})_{2} \mathrm{D}$ induces intestinal calcium and phosphorus absorption and stimulates osteoclast activity, thereby increasing calcium and phosphorous availability in the blood. ${ }^{10,11}$ Thus, vitamin $\mathrm{D}$ is very important in maintaining bone health. In addition, recent evidence suggests that vitamin D is also an important in promoting cardiovascular health and preventing chronic diseases (diabetes mellitus, autoimmune disorders, and various cancers). ${ }^{12,13}$

One of the major reasons for the worldwide spread of this nutritional disorder has been deficient awareness about the importance of vitamin $\mathrm{D}$, its benefits on health, and prevention of deficiency state across different populations. ${ }^{14,15}$ Vitamin D deficiency (VDD) develops due to insufficient knowledge and practice towards vitamin D, as well as environmental, biological and socioeconomic factors resulting in sun-avoidance behaviour, sedentary indoor lifestyle, increased screen-based activities. $^{16}$ Although, it is expected that medical professionals and students would be more aware regarding the importance of vitamin $\mathrm{D}$, but the huge academic and professional burden allows for little sun exposure or exercise and thus putting them at a higher risk for developing Vitamin D deficiency (VDD). Medical students are the future healthcare providers of the community and should therefore be the target for inducing some long-term changes it in. ${ }^{17}$ If awareness is created among them this next generation professionals could influence the progression of future health education programs, policy development, formation of social norms and beliefs about health and health promoting behaviours. $^{18}$

Vitamin D deficiency (VDD) is widely prevalent in this part of the country (Kashmir valley, India) with a study reporting $83 \%$ prevalence in healthy adults. The prevalence among females $(94.4 \%)$ was much higher as compared to males $(76.6 \%) .{ }^{19}$ Not much research work has been done so far in this part of the country to understand the knowledge, attitudes and practice of female students regarding this nutrient. Hence, this study was conducted to assess the assesses the awareness of female medical students regarding the importance of vitamin D and the prevention of its deficiency among them.

\section{METHODS}

This cross-sectional study was carried among female students of GMC Srinagar and SKIMS Medical College, Jammu and Kashmir, India from December 2018 to February 2019. A total of 113 female students (of first and second year) participated in the study. The inclusion criteria were, participants being female students willing to participate in the study. Those unwilling to participate were excluded from the study. The main objective of the study that was to assess vitamin D knowledge among them was fully explained to them. Confidentiality was assured. A self-administered questionnaire consisting of two parts was constructed with the help of previously conducted studies but relevant to local context. ${ }^{20}$ The first part of the questionnaire was for identifying socio-demographic characters of the participants like age, residence, religion, income and food preferences. The second half consisted of 12 multiple-choice questions focusing on the knowledge related to vitamin D (like source, effects of vitamin D deficiency, prevention and management of deficiency, etc.). The questionnaires were distributed among the students during a lecture schedule in presence of the researcher. Use of phone or access to internet were not allowed. After collecting the questionnaires from the participants, the correct answers were explained to them in the form of a lecture which was followed by a group discussion to increase their knowledge regarding the "sunshine" vitamin.

Data was collected and grouped using computer software MS Excel. Descriptive statistics was used to characterize the study population. Frequency tables were constructed and presented as percentages to identify the participants knowledge regarding vitamin D.

\section{RESULTS}

The sociodemographic characteristics of study population are given in Table 1.

Table 1: Socio demographic characteristics of the participants.

\begin{tabular}{|lll|}
\hline Studied variable & No. of students & $\%$ \\
\hline Age (yrs) & & \\
\hline $17-20$ & 74 & 65.48 \\
\hline$>20$ & 39 & 34.51 \\
\hline Total & 113 & 100 \\
\hline Residence & & \\
\hline Rural & 62 & 54.86 \\
\hline Urban & 51 & 45.13 \\
\hline Total & 113 & 100 \\
\hline Religion & & \\
\hline Muslims & 68 & 61.06 \\
\hline Hindus & 41 & 36.28 \\
\hline Others & 4 & 3.53 \\
\hline Total & 113 & 100 \\
\hline Family income $\mathbf{( R s} / \mathbf{m})$ & \\
\hline$>30000$ & 14 & 12.38 \\
\hline $30000-50000$ & 52 & 46.01 \\
\hline$>50000$ & 47 & 41.59 \\
\hline Total & 113 & 100 \\
\hline Food preferences & & 89.38 \\
\hline Non veg & 101 & 10.61 \\
\hline Veg & 12 & 100 \\
\hline Total & 113 & \\
\hline & & \\
\hline
\end{tabular}


Nearly two third of the participants were of the age group $17-20$ years $(65.48 \%)$ and only $34.51 \%$ belonged to the $>20$ years group. Participants belonging to rural areas formed $54.86 \%$ while those belonging to urban areas formed $45.13 \%$ of the study population. Muslims formed the major religious group $(61.06 \%)$ followed by Hindus $(36.18 \%)$. The average monthly family income was between Rs. 30000-50000 for $46.01 \%$ participant and >Rs. 50000 for $41.59 \%$. Majority were non-vegetarians $(89.38 \%)$ and only $10.61 \%$ were vegetarians. The results of the study showed that majority of participants had adequate knowledge about main source of vitamin D (97.34\%), its dietary sources $(77.87 \%)$ and the site of synthesis $(89.39 \%)$. They also had adequate knowledge about the effect of vitamin D on bone health $(84.07 \%)$, main effects of deficiency on bone health $(84.07 \%)$, identification of high-risk groups $(71.68 \%)$ and importance of supplements in management of deficiency (69.02\%). However, majority of participants had poor knowledge about the epidemic nature of deficiency status in Kashmir, India and only $39.20 \%$ participants answered this question on knowledge correctly. They had poor knowledge regarding some other questions as well like only $21.23 \%$ knew about the sufficient serum levels, only $20.35 \%$ knew about other effects of deficiency, only $19.46 \%$ knew about recommended daily allowance, only $7.96 \%$ knew about the adequate sun exposure and only $4.42 \%$ knew about effects of excess vitamin D (Table 2).

Table 2: Knowledge of the participants regarding vitamin $D$, its benefits and management of deficiency.

\begin{tabular}{|ll|}
\hline Questions & \% correct responses \\
\hline Main sources of vitamin D & 97.34 \\
\hline Dietary sources & 77.87 \\
\hline Site of synthesis & 89.38 \\
\hline Importance-Main & 84.07 \\
\hline RDA & 19.46 \\
\hline Sun exposure (time/duration) & 4.42 \\
\hline $\begin{array}{l}\text { Vitamin D deficiency-main } \\
\text { effects/others }\end{array}$ & 81.41 \\
\hline High risk groups & 71.68 \\
\hline $\begin{array}{l}\text { Status of vitamin D deficiency } \\
\text { in Kashmir, India }\end{array}$ & 39.20 \\
\hline Serum levels-sufficiency & 21.23 \\
\hline Management of deficiency & 69.02 \\
\hline Effects of vitamin D excess & 7.96 \\
\hline
\end{tabular}

\section{DISCUSSION}

Vitamin D deficiency, a very common underdiagnosed condition has started to receive increasing attention in the world. ${ }^{21}$ Present study is one of the first studies that assesses the awareness of female medical students regarding the importance of vitamin $\mathrm{D}$ and the prevention of its deficiency as very little research has been conducted in this area in this part of the world. The present study indicated that almost all the participants recognized the importance of exposure to sunlight $(97.34 \%)$ and the majority correctly identified the dietary sources of vitamin D (77.87\%) and the site of synthesis (89.39\%). The majority of study participants correctly pointed out the effect of vitamin D on bone health $(84.07 \%)$, recognised the main effects of deficiency on bone health $(84.07 \%)$, identified the high-risk groups $(71.68 \%)$ and knew about the importance of supplements in management of deficiency $(69.02 \%)$. The deficiency status in Kashmir, India was identified as an epidemic by $39.20 \%$ participants. Only $21.23 \%$ knew about the sufficient serum levels, only $20.35 \%$ knew about other effects of deficiency, only $19.46 \%$ knew about recommended daily allowance, and only $7.96 \%$ knew about the adequate sun exposure $4.42 \%$ knew about effects of excess vitamin D. A study conducted in Delhi, India among medical students (both males and females) found similar levels of awareness regarding effects of deficiency on bone, other effects of deficiency, identification of high risk groups, use of supplements in management of deficiency and status as an epidemic in the region. ${ }^{20}$ However, this study reported different levels of awareness regarding main/dietary sources of the vitamin and adequate sun exposure. Present findings are also consistent with another study conducted among science (biotechnology) students which found that majority of the students knew that sunlight was the main source of Vitamin $\mathrm{D}$, majority of students did not know about the required minimum daily intake of Vitamin D or time/duration of sun exposure. $^{22}$

The results of the present study showed that the participants had good knowledge regarding some aspects while knowledge for other aspects was poor. Like the previously conducted study, the present study also shows huge gaps in basic knowledge about vitamin $\mathrm{D}$, its benefits, and management of deficiency. ${ }^{20}$ Despite of being a sun sufficient country the prevalence of VDD is very high here. Sun exposure the best natural sources for prevention and treatment of vitamin D deficiency is not utilized much due to various sociocultural and dietary factors, limited outdoor activity due to urbanization, air pollutants, and negative attitudes towards sunlight with extensive use of sunscreens for "fairer" skin all attributing to high prevalence of vitamin D deficiency. ${ }^{23-25}$ Lack of awareness will increase this problem while adequate knowledge about VDD and its prevention can cause a potential decrease in the disease burden by bringing a positive change in attitude of the people. This emphasizes the need for sensitization of medical undergraduates early in their training regarding vitamin $\mathrm{D}$, its importance, and prevention and treatment of deficiency.

Awareness about vitamin D at initial stage of medical profession would not only benefit their own health but also imbibe a health-related behaviour change and increase their knowledge as future medical professionals who would then help in spreading the awareness in the community. ${ }^{26}$ Present study was the first in the state that assesses the knowledge regarding vitamin D among female medical students. The study had some limitations also like cross sectional nature and small sample size. 


\section{CONCLUSION}

The present study showed that there are some gaps in awareness about vitamin $\mathrm{D}$, its benefits, and management of deficiency among female medical students. The majority of participants had adequate knowledge about main source/dietary source of vitamin D, the site of synthesis, effect of vitamin $\mathrm{D}$ on bone health, main effects of deficiency on bone health, identification of high-risk groups and importance of supplements in management of deficiency. However, majority had inadequate knowledge about the epidemic state of VDD, RDA, time /duration of sun exposure and other effects of deficiency. Thus, the need of the hour is to create more awareness among students about this epidemic which would induce an attitude change in them benefiting their own as well as community health.

\section{Funding: No funding sources}

Conflict of interest: None declared

Ethical approval: The study was approved by the Institutional Ethics Committee

\section{REFERENCES}

1. Holick MF. The vitamin D epidemic and its health consequences. J Nutrition. 2005;135(11):2739S-48S.

2. Khalsa S. Vitamin D Revolution. Hay House, Inc; 2009.

3. Harinarayan CV, Joshi SR. Vitamin D status in Indiaits implications and remedial measures. JAPI. 2009;57:40-8.

4. Marwaha RK, Sripathy G. Vitamin D and bone mineral density of healthy school children in northern India. Ind J Med Res. 2008;127(3):239.

5. Harinarayan CV. Prevalence of vitamin D insufficiency in postmenopausal south Indian women. Osteoporosis Int. 2005;16(4):397-402.

6. Sharman IM. Vitamin D: Anti-rachitic factor and kidney hormone. Nutrition Food Sci. 1975;75(4):4-7.

7. Houghton LA, Vieth R. The case against ergocalciferol (vitamin D2) as a vitamin supplement. Am J Clin Nutrition. 2006;84(4):694-7.

8. Holick MF. Vitamin D: A millenium perspective. J Cell Biochem. 2003;88(2):296-307.

9. Holick MF. Vitamin D deficiency. New Eng J Med. 2007;357(3):266-81.

10. As D. Vitamin D. Am J Physiol Renal Physiol. 2005;289:F8-28.

11. Omdahl JL, Gray RW, Boyle IT, Knutson J, DeLuca HF. Regulation of metabolism of 25hydroxycholecalciferol by kidney tissue in vitro by dietary calcium. Nature New Biol. 1972;237(71):63.

12. Heaney RP. Bone health. Am J Clin Nutrition. 2007;85(1):300S-3S.

13. Holick MF. High prevalence of vitamin D inadequacy and implications for health. Mayo Clin Proceedings. Elsevier. 2006;81(3):353-73.
14. Mithal A, Wahl DA, Bonjour JP, Burckhardt P, Dawson-Hughes B, Eisman JA, et al. IOF Committee of Scientific Advisors (CSA) Nutrition Working Group. Global vitamin D status and determinants of hypovitaminosis D. Osteoporosis Int 2009;20(11):1807-20.

15. Hagenau T, Vest R, Gissel TN, Poulsen CS, Erlandsen M, Mosekilde L, et al. Global vitamin D levels in relation to age, gender, skin pigmentation and latitude: an ecologic meta-regression analysis. Osteoporosis Int. 2009;20(1):133.

16. Bothmer MI, Fridlund B. Gender differences in health habits and in motivation for a healthy lifestyle among Swedish university students. Nursing Heal Sci. 2005;7(2):107-18.

17. Edis Z, Bloukh SH. Vitamin D deficiency-main factors affecting the serum 25-Hydroxyvitamin $\mathrm{D}(25$ $(\mathrm{OH}) \mathrm{D})$ status and treatment options. Int $\mathrm{J}$ Res. 2016;3(01):197-211.

18. Haase A, Steptoe A, Sallis JF, Wardle J. Leisure-time physical activity in university students from 23 countries: associations with health beliefs, risk awareness, and national economic development. Preventive Med. 2004;39(1):182-90.

19. Zargar AH, Ahmad S, Masoodi SR, Wani AI, Bashir MI, Laway BA, et al. Vitamin D status in apparently healthy adults in Kashmir Valley of Indian subcontinent. Postgradua Med J. 2007;83(985):713-6.

20. Lhamo Y, Chugh PK, Gautam SR, Tripathi CD. Epidemic of Vitamin D deficiency and its management: awareness among indian medical undergraduates. J Env Public Heal. 2017;2017.

21. Hossein-nezhad A, Holick MF. Vitamin D for health: a global perspective. Mayo clinic proceedings. Elsevier. 2013;88(7):720-55.

22. Arora H, Dixit V, Srivastava N. Evaluation of knowledge, practices of vitamin D and attitude toward sunlight among Indian students. Evaluation. 2016;9(1):308.

23. Gorham ED, Garland CF, Garland FC, Grant WB, Mohr SB, Lipkin M, et al. Vitamin D and prevention of colorectal cancer. J Steroid Biochem Molecular Biol. 2005;97(1-2):179-94.

24. Deschasaux M, Souberbielle JC, Partula V, Lécuyer L, Gonzalez R, Srour B, et al. What do people know and believe about vitamin D?. Nutrients. 2016;8(11):718.

25. Gupta A. Vitamin D deficiency in India: prevalence, causalities and interventions. Nutrients. 2014;6(2):729-75.

26. Nilsson M, Ohlsson C, Odén A, Mellström D, Lorentzon M. Increased physical activity is associated with enhanced development of peak bone mass in men: a five-year longitudinal study. J Bone Mineral Res. 2012;27(5):1206-14.

Cite this article as: Nowreen N, Hameed R. Awareness regarding the importance of vitamin D and prevention of its deficiency among female undergraduate medical students. Int J Basic Clin Pharmacol 2019;8:865-8. 